\title{
Effects of Green Wavelength Light on Antioxidant Responses in Olive Flounder Paralichthys olivaceus Exposed to Starvation and Re-feeding
}

\author{
Cheol Young Choi ${ }^{1, *}$ (D) Jin Ah Song ${ }^{1}$, Young-Ung Choi ${ }^{2}$, Tae Ho Lee ${ }^{1}$, Han Seok Ryu ${ }^{1}$
}

${ }^{1}$ Division of Marine BioScience, National Korea Maritime and Ocean University, Busan 49112, Republic of Korea.

${ }^{2}$ Marine Ecosystem and Biological Research Center, KIOST, Busan 49111, Republic of Korea.

\section{Article History}

Received Oct 27, 2019

Accepted Jun 4, 2020

First Online Jun 11, 2020

\section{Corresponding Author}

Tel.: +82514104756

E-mail:choic@kmou.ac.kr

\section{Keywords}

Antioxidant Enzymes

Green Wavelength

Oxidative Stress

Paralichthys olivaceus

Refeeding

Starvation

\begin{abstract}
An understanding of responses to antioxidant enzymes in different starvation and refeeding protocols is critical in the aquaculture of fish. This study investigated the effect of green wavelength $(520 \mathrm{~nm})$ on the antioxidant response of the olive flounder, Paralichthys olivaceus, exposed to different starvation and re-feeding protocols for 4 weeks. We analyzed mRNA expression of peroxisome proliferator-activated receptor alpha (PPAR $\alpha$ ) and the levels of plasma glucose, superoxide dismutase (SOD), and catalase (CAT), hydrogen peroxide $\left(\mathrm{H}_{2} \mathrm{O}_{2}\right)$, and lipid peroxidation (LPO). Furthermore, we performed immunohistochemistry staining $(\mathrm{IHC})$ to observe the SOD expression in the liver visually. We found that expression and activity of antioxidant enzymes (PPAR $\alpha$, SOD, and CAT), as well as plasma $\mathrm{H}_{2} \mathrm{O}_{2}$ and LPO levels, increased significantly during the starvation period compared to the fed group. However, antioxidant enzymes and oxidative stress increased during the fasting period were significantly decreased during the re-feeding period, especially in the group irradiated with green light. Also, using IHC staining, we found that green light and different feeding protocols affected the expression of SOD in the liver. These findings show that irradiation with green light was effective at alleviating the increased oxidative stress during starvation and re-feeding periods in olive flounder.
\end{abstract}

\section{Introduction}

Recent studies have reported that light of a particular wavelength can act as an important environmental factor in regulating the endocrine signals of fish in captivity, and can also affect the expression of oxidative stress through regulation of reactive oxygen species (ROS) production (Choi et al., 2012; Choi et al., 2018). Recently, green LED light irradiation has been reported to reduce oxidative stress in starved fish effectively and has attracted much attention from researchers (Choi et al., 2018). Furthermore, a green wavelength has a positive effect on growth and immunity in fish exposed to various environmental stresses (Shin, Lee, \& Choi, 2012).
The liver is known to be the organ responsible for energy metabolism and homeostasis (Babaei, Kenari, Hedayati, Sadati, \& Meton, 2016). It produces glucose through the decomposition of glycogen (catabolism), the first substrate used as an energy metabolite in fish exposed to changes in feeding environment such as fasting and re-feeding (Mohapatra et al., 2015). The peroxisome proliferator-activated receptors (PPARs), which are produced in the liver, are the main transcriptional regulators of antioxidant defense as well as energy homeostasis and are affected by the nutritional status of the organism (Picard \& Auwerx, 2002; Rakhshandehroo, Knoch, Muller, \& Kersten, 2010). In the nucleus, PPARs are hormone receptors with three subtypes $(\alpha, b$, and $\gamma)$ that regulate lipid 
metabolism and energy homeostasis (Griffin, 2015). In particular, PPAR $\alpha$ expressed in the liver not only regulates glucose homeostasis through the gluconeogenesis process (Li et al., 2017) but also directly affects antioxidant mechanisms by direct transcriptional control of the major antioxidant enzyme, superoxide dismutase (SOD) (Rakhshandehroo et al., 2010).

Additionally, changes in the feeding environment lead to changes in cell activity in fish and increase the production of ROS that cause oxidative stress (Choi, Choi, Choi, \& Yoo, 2018). Representative ROS such as superoxide $\left(\mathrm{O}^{-}\right)$, hydrogen peroxide $\left(\mathrm{H}_{2} \mathrm{O}_{2}\right)$, hydroxyl radicals $\left(\mathrm{OH}^{-}\right)$, and singlet oxygen $\left({ }^{1} \mathrm{O}_{2}\right)$ are overproduced in the fish body, increasing lipid peroxidation (LPO), oxidizing cellular components such as lipid, proteins, and DNA, and inducing apoptosis, eventually negatively affecting cell survival (Kim \& Yang, 2013; Regoli \& Giuliani, 2014). Thus, fish activate the antioxidant defense mechanism to protect themselves from ROS caused by changes in the feeding environment (Pandey et al., 2003; Yang et al., 2019). Antioxidant enzymes involved in such defense mechanisms are SOD, catalase (CAT), and glutathione peroxidase (GPx) (Regoli \& Giuliani, 2014). Firstly, SOD converts $\mathrm{O}_{2}^{-}$into $\mathrm{O}_{2}$ and $\mathrm{H}_{2} \mathrm{O}_{2}\left(2 \mathrm{O}_{2}^{-}+\mathrm{H}^{+} \rightarrow \mathrm{H}_{2} \mathrm{O}_{2}+\mathrm{O}_{2}\right)$, and the produced toxic material $\mathrm{H}_{2} \mathrm{O}_{2}$ is decomposed to into non-toxic material $\mathrm{H}_{2} \mathrm{O}$ and $\mathrm{O}_{2}$ by CAT and GPx $\left(2 \mathrm{H}_{2} \mathrm{O}_{2} \rightarrow 2 \mathrm{H}_{2} \mathrm{O}+\mathrm{O}_{2}\right.$ ) (Choi, Shin, Choi, \& Kim, 2012; Regoli \& Giuliani, 2014).

Recently, the aquaculture industry has focused on maintaining production efficiency, reducing feed loss, and reducing adverse environmental impacts through feeding regimes appropriate to fish species (Ali, Martínez-Llorens, Moñino, Cerdá, \& Tomás-Vidal, 2016). It is known that re-feeding after a certain period of fasting reduces feed loss and costs and achieves faster growth than that in continuously fed fish (Najafi, Salati, Yavari, \& Asadi, 2014; Yang et al., 2019).

In general, fish have hyperphagia when they are refed after fasting (Bar, 2014; Ali et al., 2016). Not only is the insufficient nutritional status due to fasting satisfied through the re-feeding, but the fish also show a higher growth rate than those fed continuously (Won \& Borski, 2013). In addition, fish are known to regulate metabolic and energy homeostasis through the liver to adapt to unfavorable and irregular feeding environments such as feed deprivation (Pérez-Jiménez, Guedes, Morales, \& Oliva-Teles, 2007). Although previous studies based on unfavorable feeding regimes have been widely reported for aquaculture species, most have investigated hematological and physiological responses and focused on growth index analysis and stress response (Antonopoulou et al., 2013). Therefore, further studies on the regulation of energy metabolism and changes in antioxidant enzymes in fish exposed to different feeding environments, such as fasting and refeeding, need to be carried out.

Therefore, in this study, we investigated the effect of green wavelength on the expression of antioxidant responses induced by starvation and re-feeding in olive flounder Paralichthys olivaceus. Firstly, the flounders were exposed to each experimental environment for 4 weeks, and the PPAR $\alpha$ mRNA expression, SOD and CAT plasma levels, as well as $\mathrm{H}_{2} \mathrm{O}_{2}, L P O$, and glucose concentration in plasma were measured. In addition, SOD molecules were stained in liver cells by immunohistochemical staining (IHC) to observe the expression changes of the antioxidant enzyme SOD visually.

\section{Materials and Methods}

\section{Experimental Fish and Sampling}

The handling of all experimental samples complied with the Animal Protection Act guidelines issued by the Institutional Animal Care Use Committee of Korea. Juvenile olive flounder Paralichthys olivaceus ( $n=160$, length $11.2 \pm 0.6 \mathrm{~cm}$; weight $11.7 \pm 1.2 \mathrm{~g}$ ) were purchased from a commercial aquarium (Gochang, Korea), and fish were subsequently allowed to acclimate in eight 300-L circulation filter tanks prior to laboratory experiments. For the experiment, the tanks were divided into four groups, with two tanks in each group and 25 fish per tank. All experimental fish were exposed to $20^{\circ} \mathrm{C}$ and 35 psu salinity. The photoperiod consisted of a 12-h light:12-h dark cycle (lights were turned on at 07:00 and turned off at 19:00 each day). During the feeding periods of the experiment, fish were fed twice daily at 09:00 and 17:00 with floating commercial feed containing $50 \%$ crude protein (KOFEC Feed, Korea). Five fish from each experimental group were sampled at 1week intervals over 4 weeks. Prior to blood and tissue collection, fish were anesthetized with $200 \mu \mathrm{g} \mathrm{L}^{-1} 2$ phenoxyethanol (Daejung Co., Korea) to minimize stress. Blood was collected rapidly from the caudal vein using a 1-mL syringe coated with heparin. Plasma samples were separated by centrifugation $\left(4^{\circ} \mathrm{C}, 10,000\right.$ $\times \mathrm{g}$, for $10 \mathrm{~min}$ ) and stored at $-80^{\circ} \mathrm{C}$ until analysis.

\section{Experimental Conditions}

The experimental groups were irradiated with green $(520 \mathrm{~nm})$ light-emitting diode (LED) $\left(1.0 \mathrm{~W} / \mathrm{m}^{2}\right.$ intensity, Daesin, LED Co., Korea) or white fluorescent bulb $\left(0.96 \mathrm{~W} / \mathrm{m}^{2}\right.$ intensity, Philips, Netherlands) during 4 weeks at different feeding protocols (Figure 1). Different feeding groups were designed as follows; first group (4F) fed for 4 weeks; the second group (1S-3F) starved 1 week and then refed for 3 weeks; the third group (2S-2F) starved 2 weeks and refed 2 weeks; the fourth group (4S) starved for 4 weeks. Of the above experimental groups, we used $4 \mathrm{~F}$ as the control group and irradiated with a green LED or white fluorescent bulb. The light sources were placed $50 \mathrm{~cm}$ above the water surface, and the depth of the water column was $50 \mathrm{~cm}$. The irradiance levels at the bottom of the tanks were maintained at approximately $1.0 \mathrm{~W} / \mathrm{m}^{2}$ using a spectrometer (MR-16; Rainbow Light Technology, 


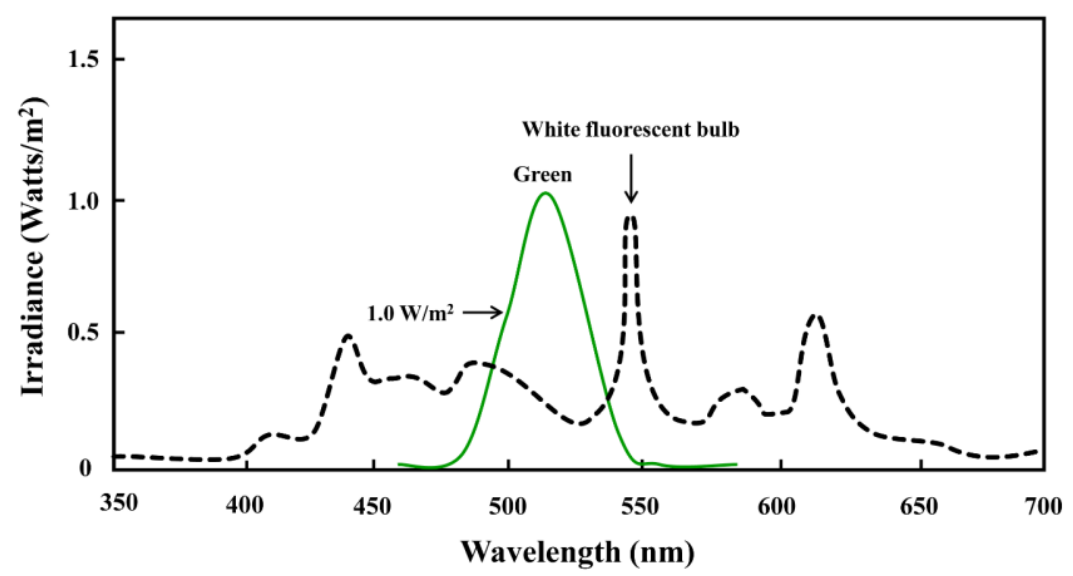

Figure 1. Spectral profiles of the green $(520 \mathrm{~nm})$ LED and the white fluorescent bulb (dotted line) with light intensity of 1.0 $\mathrm{W} / \mathrm{m}^{2}$.

Taiwan) and a photoradiometer (HD 2102.1; Delta OMH Co., Italy).

\section{Survival Rate and Weight Changes}

Survival rates (\%) were determined at daily intervals for 28 days and calculated as follows: survival rate $(\%)=$ number of fish at the time of evaluation / number of fish at the beginning of the experiment $\times 100$. Weight gain (g/fish) was measured weekly for 28 days calculated as follows: weight gain = final weight-initial weight.

\section{Real-time Quantitative Polymerase Chain Reaction (qPCR)}

From each liver sample, total RNA (treated with DNase to remove genomic DNA) was extracted using the TRI Reagent ${ }^{\circledR}$ (Molecular Research Center, Inc., USA) according to the manufacturer's instructions. Then, a 2 $\mu \mathrm{g}$ sample of total RNA was reverse-transcribed in a total reaction volume of $20 \mu \mathrm{l}$ using an oligo-(dT) 15 anchor and M-MLV reverse transcriptase (Promega, USA) according to the manufacturer's protocol. The relative expression levels of PPAR $\alpha$ (GenBank Accession No. HM147767) and $\beta$-actin (GenBank Accession No. HQ386788) were determined using qPCR. The primers for qPCR were based on known sequences of olive flounder: PPAR $\alpha$ : forward (5'-ACA ATG ATG CCC TCA GCT CT-3') and reverse (5'-AGA ACT CCT CTT GGC CCA TT-3'); and $\beta$-actin: forward ( $5^{\prime}$-GGA CCT GTA TGC CAA CAC-3') and reverse (5'-TGA TCT CCT TCT GCA TCC TG-3'). qPCR amplification was performed using a Bio-Rad CFX96 ${ }^{\mathrm{TM}}$ Real-time PCR Detection System (Bio-Rad, Hercules, CA, USA) and ${ }^{2}{ }^{\text {TM }}$ SYBR Green Supermix (Bio-Rad) with the following conditions: $0.5 \mu \mathrm{l}$ of $\mathrm{CDNA}, 0.26 \mu \mathrm{M}$ of each primer, $0.2 \mathrm{mM}$ dNTP, SYBR Green, and Taq polymerase in buffer (10 mM Tris- $\mathrm{HCl}$ [pH 9.0], $50 \mathrm{mM} \mathrm{KCl}, 1.4 \mathrm{mM}$ $\mathrm{MgCl}_{2}$, and $20 \mathrm{nM}$ fluorescein) to a total volume of $25 \mu \mathrm{l}$. The qPCR process was carried out as follows: 1 cycle of initial denaturation at $95^{\circ} \mathrm{C}$ for $5 \mathrm{~min}, 35$ cycles of denaturation at $95^{\circ} \mathrm{C}$ for $20 \mathrm{~s}$ and annealing at $55^{\circ} \mathrm{C}$ for
$20 \mathrm{~s}$, followed by $5 \mathrm{~min}$ at $72^{\circ} \mathrm{C}$ for the final extension. All analyses were based on the $\mathrm{Ct}$ values of $\mathrm{PCR}$ products. The calibrated $\Delta \mathrm{Ct}$ value $(\Delta \Delta \mathrm{Ct})$ for each sample and internal controls ( $\beta$-actin) was calculated as $\Delta \Delta \mathrm{Ct}=2$-( $\Delta \mathrm{Ctsample}-\Delta \mathrm{Ctinternal}$ control).

\section{Plasma Parameter Analysis}

Plasma samples were centrifuged at $5,000 \times \mathrm{g}$ for 5 $\min$ at $4^{\circ} \mathrm{C}$. The supernatants were collected carefully, and the remained plasma was used for the analyses. The levels of SOD, CAT, and LPO activities were analyzed using an immunoassay from an ELISA kit (SOD, MBS282055; CAT, MBS705697; LPO, MBS013426; MyBioSource Inc., San Diego, USA), respectively. The absorbance was read at $450 \mathrm{~nm}$ using a plate reader. Plasma $\mathrm{H}_{2} \mathrm{O}_{2}$ levels were determined using a PeroxiDetect kit (Sigma, USA). Absorbance was read at $560 \mathrm{~nm}$, and $\mathrm{H}_{2} \mathrm{O}_{2}$ concentration was interpolated from a standard curve. Plasma glucose levels were analyzed by a dry multiplayer analytic slide method using an automatic biochemical analyzer (Fuji Dri-Chem 4000, Fujifilm, Japan).

\section{Immunohistochemistry Staining}

For identification of SOD immunoreactive expression, liver tissues were removed after 4 weeks in each experimental group. Tissues were fixed in $10 \%$ neutral buffered formalin for $24 \mathrm{~h}$ at room temperature, dehydrated in ethanol, and then xylene. Tissue was embedded in molten paraffin and, after the paraffin solidified, paraffin blocks were kept at $4^{\circ} \mathrm{C}$ until sectioning. Embedded tissues were sectioned to $6-\mu \mathrm{m}$ thickness and floated in a $50^{\circ} \mathrm{C}$ water bath containing distilled water. Sections were mounted onto gelatincoated slides and incubated overnight at room temperature. The slides were deparaffinized and rehydrated by immersing them in xylene, ethanol, and distilled water. Primary mouse anti-SOD1 antibody (NBP1-47443; 1/1,000 dilution; Novus Biologicals ${ }^{\circledR}$; USA) diluted in $1 \%$ animal serum $1 \mathrm{X}$ phosphate-buffered 
saline with Tween detergent (PBS-T) was added, and slides were incubated at room temperature for 1-2 hours. Afterward, sections were washed twice with $1 \%$ serum PBS-T for 10 min each. A biotinylated secondary antibody was added, and slides were incubated at room temperature for 1 hour. After washing each section twice with $1 \%$ serum PBS-T for $10 \mathrm{~min}, \mathrm{ABC}-\mathrm{HRP}$ reagent was added and sections were incubated at room temperature for 1 hour. 3,3'-Diaminobenzidine (DAB) working solution was applied to the tissue sections, and the resulting chromogenic reaction was monitored (i.e., epitope sites turned brown). Slides were counterstained with hematoxylin, dehydrated, and mounted with Canada balsam for observation under a light microscope.

\section{Statistical Analysis}

All data were analyzed using SPSS version 25.0 (IMB SPSS Inc., USA). All parameters analyzed (i.e., exposure to different concentrations and sampling after different exposure times) were compared using twoway ANOVA. Where significance was indicated, the Tukey post hoc test for multiple comparisons was used. ANOVA assumptions (Levene's test for homogeneity of variances and the Kolmogorov-Smirnov test for data normality) were previously checked. The significance level adopted was 95\% ( $P<0.05)$. Values are expressed as the means \pm standard deviation (SD).

\section{Results}

\section{Changes in Body Weight}

Survival rate (\%) and weight gain (g/fish) of olive flounder during the different feeding regimes are presented in Table 1 . The survival rate was not significantly affected by the feeding regime, ranging from $95.3 \%$ to $99.1 \%$. Comparison of weight gain showed that $4 \mathrm{~F}$ (white; $21.7 \pm 2.63$ g, green; $22.9 \pm 2.57$ g) and irradiation of green light to 1 S-3F (21.8 $\pm 1.56 \mathrm{~g})$ had significantly higher weight gain compared to the other treatments. After this, the weight gain for IS-3F with white light was greater than that for $2 \mathrm{~S}-2 \mathrm{~F}$, which in turn was greater than 4S.

\section{Changes in Plasma Glucose Levels}

Plasma glucose level responses to different feeding regimes and light sources were assessed (Figure 2). There were significant interactive effects between factors $(P<0.05)$. Plasma glucose levels remained constant in $4 \mathrm{~F}$, while they decreased in the other groups (1S-3F, 2S-2F, and 4S). In $1 \mathrm{~S}-3 \mathrm{~F}$ and $2 \mathrm{~S}-2 \mathrm{~F}$, plasma glucose levels significantly increased after re-feeding. Moreover, the groups exposed to green light irradiation had higher plasma glucose levels than those exposed to white light.

\section{Changes in PPARa Expression and SOD and CAT Activities}

PPAR $\alpha$ mRNA expressions in liver tissues, and plasma SOD and CAT activities in response to the starvation and re-feeding periods are shown in Figures 3 to 5 . There were significant interactive effects between factors $(P<0.05)$. The $4 F$ group showed no significant differences in mRNA expression of PPAR $\alpha$, or activities of SOD and CAT throughout the experiment. However, the other groups showed significantly increased activity of these enzymes during starvation but significantly decreased activity during re-feeding; also, enzyme activity significantly decreased under green LED light irradiation. In addition, PPAR $\alpha$ expression, and the activity of SOD and CAT at 4 weeks, showed that $1 \mathrm{~S}-3 \mathrm{~F}$ was not significantly different from the $4 \mathrm{~F}$, while the other groups were significantly higher.

\section{Immunohistochemistry Staining of SOD During the Experimental Period}

We observed the expression of SOD evaluated by immunohistochemistry during the starvation and refeeding periods (Figure 6). These results showed similar trends to those of plasma SOD activities (Figure 4). The immunohistochemical expression of SOD did not differ

Table 1. Changes in weight gain and survival rate of the olive flounder exposed to 4 different feeding conditions under 2 different light sources for 4 weeks

\begin{tabular}{lcccc}
\hline Treatments & Survival rate (\%) & Initial weight (g/fish) & Final weight (g/fish) & Weight gain (g/fish) \\
\hline 4F white & $98.4 \pm 1.53$ & $11.4 \pm 0.91$ & $32.2 \pm 3.1$ & $21.7 \pm 2.63^{\mathrm{a}}$ \\
4F green & $99.1 \pm 0.82$ & $11.7 \pm 1.13$ & $34.4 \pm 3.7$ & $22.9 \pm 2.57^{\mathrm{a}}$ \\
1S-3F white & $97.8 \pm 2.23$ & $11.6 \pm 1.01$ & $30.5 \pm 3.3$ & $19.2 \pm 1.87^{\mathrm{b}}$ \\
1S-3F green & $98.1 \pm 1.94$ & $11.5 \pm 1.07$ & $32.6 \pm 2.9$ & $21.8 \pm 1.56^{\mathrm{a}}$ \\
2S-2F white & $96.4 \pm 2.51$ & $11.4 \pm 1.05$ & $20.2 \pm 2.7$ & $9.8 \pm 1.35^{\mathrm{c}}$ \\
2S-2F green & $96.8 \pm 2.62$ & $11.6 \pm 0.98$ & $22.7 \pm 3.1$ & $11.1 \pm 1.53^{\mathrm{c}}$ \\
4S white & $95.3 \pm 2.55$ & $11.7 \pm 1.17$ & $12.1 \pm 1.6$ & $0.5 \pm 0.32^{\mathrm{d}}$ \\
4S green & $95.7 \pm 2.41$ & $11.4 \pm 1.03$ & $12.3 \pm 1.8$ & $0.7 \pm 0.57^{\mathrm{d}}$ \\
\hline
\end{tabular}

The values are mean \pm SD $(n=5)$. The different lower-case letters indicate significant differences based on exposure to the different light and period $(P<0.05)$. 

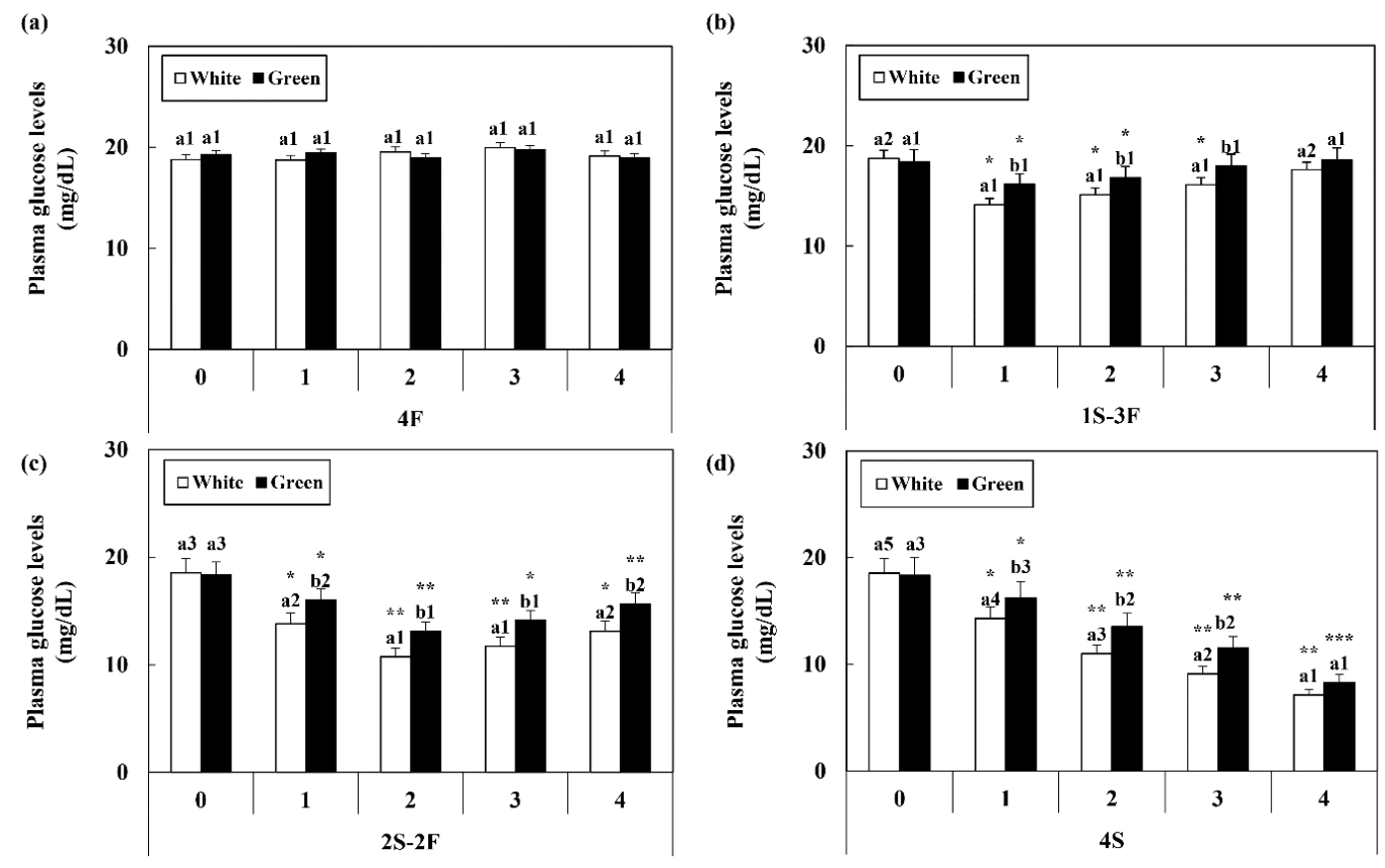

Time after experimental periods (week)

Time after experimental periods (week)

Figure 2. Plasma glucose levels at different starvation/re-feeding protocols under different types of light. a: 4 weeks fed (4F), b: 1 week starved and 3 weeks fed (1S-3F), c: 2 weeks starved, and 2 weeks fed (2S-2F), d: 4 weeks starved (4S), white: white fluorescent bulb, green: green wavelength LED. Different lower-case letters indicate significant differences between types of light in fish within the same period $(P<0.05)$. Different numbers indicate significant difference between periods with the same light type $(P<0.05)$. Asterisk symbols $\left({ }^{*}\right)$ indicate significant differences $(P<0.05)$ between different starvation/re-feeding periods within the same light type and sampling point. All values are means $\pm \operatorname{SD}(n=5)$.

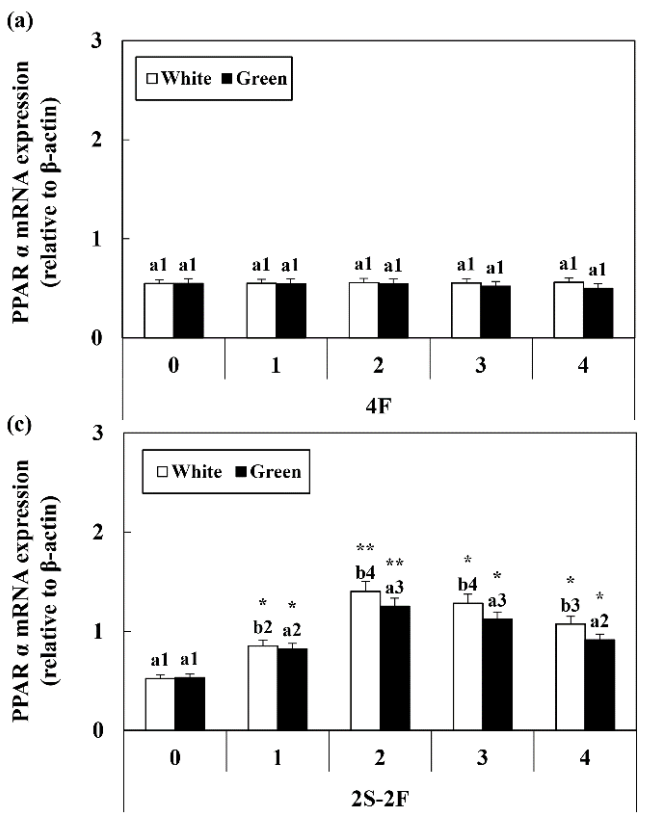

Time after experimental periods (week)

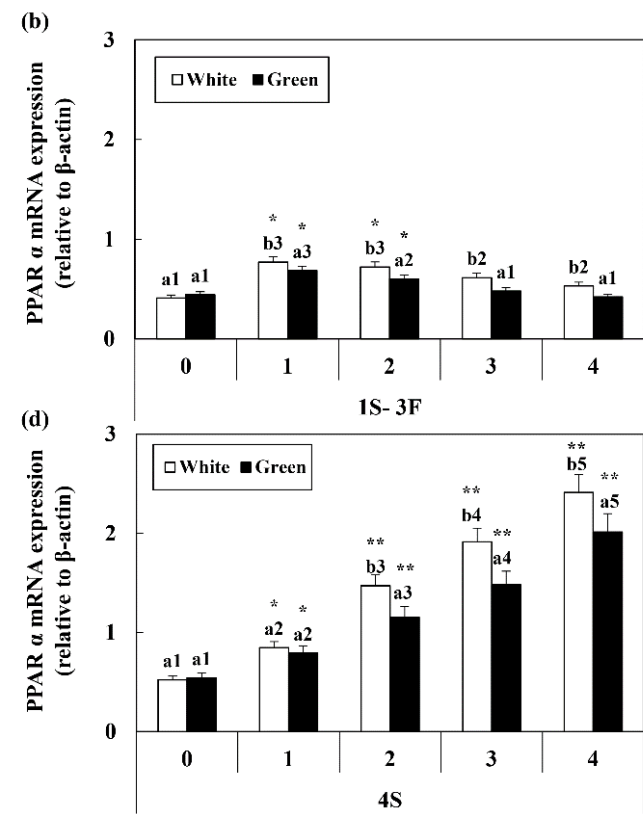

Time after experimental periods (week)

Figure 3. PPAR $\alpha$ mRNA expression levels in the liver of olive flounders exposed to different starvation/re-feeding protocols under different types of light. a: 4 weeks fed (4F), b: 1 week starved and 3 weeks fed (1S-3F), c: 2 weeks starved, and 2 weeks fed (2S-2F), d: 4 weeks starved (4S), white: white fluorescent bulb, green: green wavelength LED. Different lower-case letters indicate significant differences between types of light in fish within the same period $(P<0.05)$. Different numbers indicate significant differences between periods with the same light type $(P<0.05)$. Asterisk symbols $\left({ }^{*}\right)$ indicate significant differences $(P<0.05)$ between different starvation/re-feeding periods within the same light type and sampling point. All values are means $\pm \mathrm{SD}(n=5)$. 
(a)
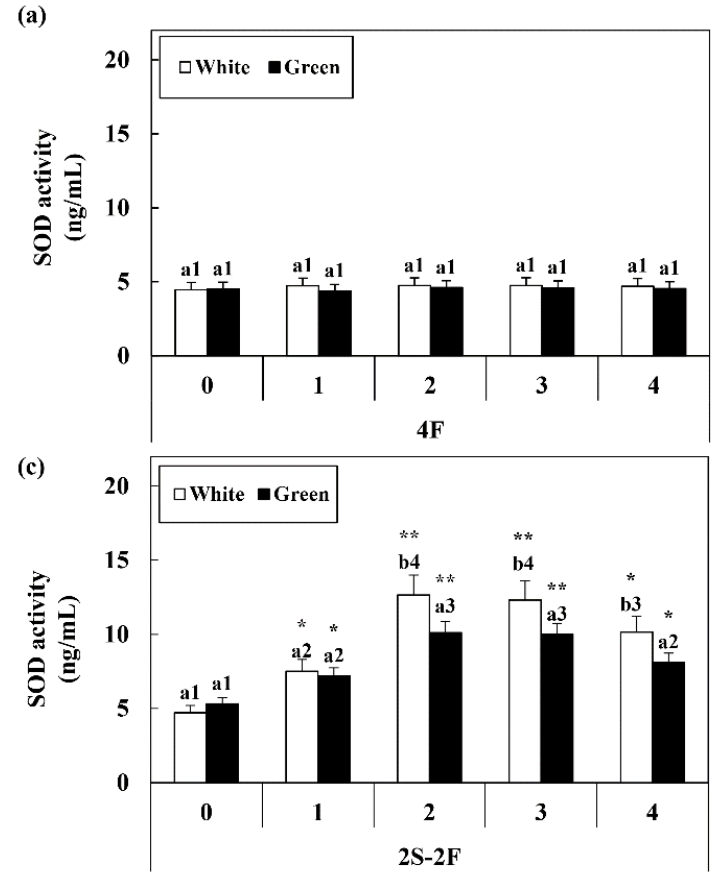

Time after experimental periods (week) (b)

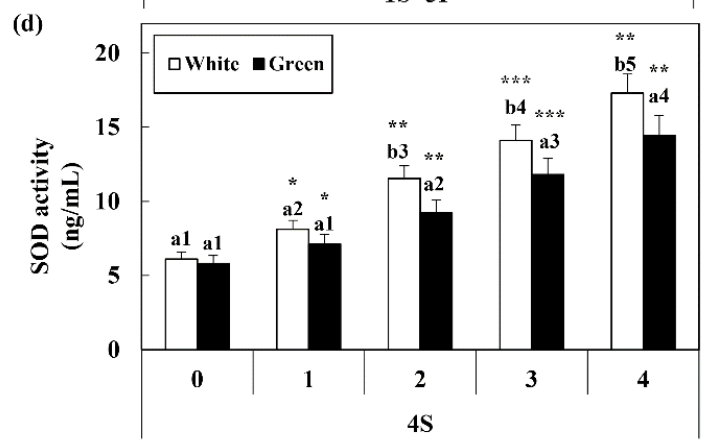

Time after experimental periods (week)

Figure 4. Plasma SOD levels at different starvation/re-feeding protocols under different types of light. a: 4 weeks fed (4F), b: 1 week starved and 3 weeks fed (1S-3F), c: 2 weeks starved, and 2 weeks fed (2S-2F), d: 4 weeks starved (4S), white: white fluorescent bulb, green: green wavelength LED. Different lower-case letters indicate significant differences between types of light in fish within the same period $(P<0.05)$. Different numbers indicate significant differences between periods with the same light type $(P<0.05)$. Asterisk symbols $(*)$ indicate significant differences $(P<0.05)$ between different starvation/refeeding periods within the same light type and sampling point. All values are means $\pm \operatorname{SD}(n=5)$.
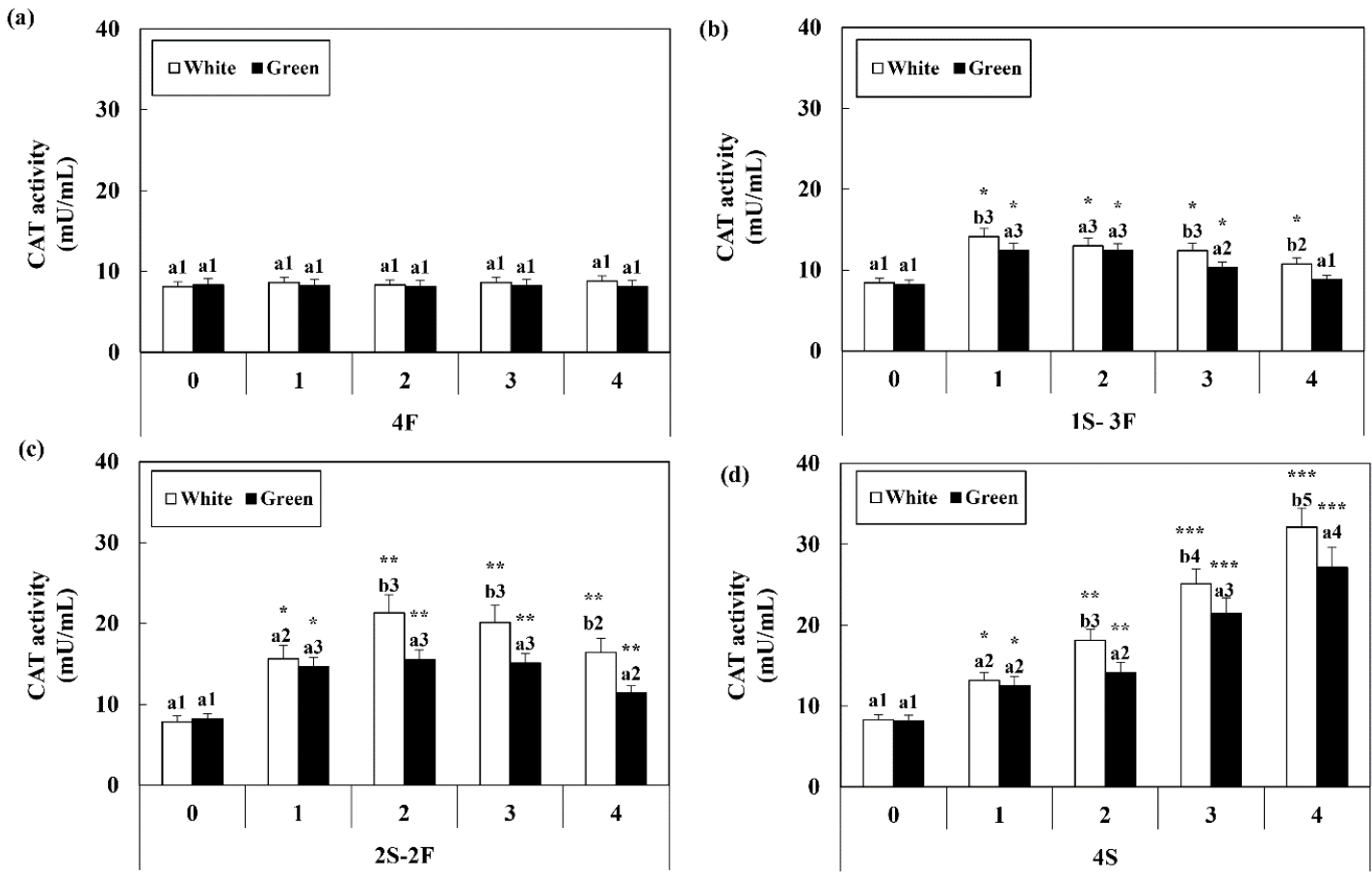

Time after experimental periods (week)

Time after experimental periods (week)

Figure 5. Plasma CAT levels at different starvation/re-feeding protocols under different types of light. a: 4 weeks fed (4F), b: 1 week starved and 3 weeks fed (1S-3F), c: 2 weeks starved, and 2 weeks fed (2S-2F), d: 4 weeks starved (4S), white: white fluorescent bulb, green: green wavelength LED. Different lower-case letters indicate significant differences between types of light in fish within the same period $(P<0.05)$. Different numbers indicate significant differences between periods with the same light type $(P<0.05)$. Asterisk symbols $(*)$ indicate significant differences $(P<0.05)$ between different starvation/refeeding periods within the same light type and sampling point. All values are means $\pm \operatorname{SD}(n=5)$. 


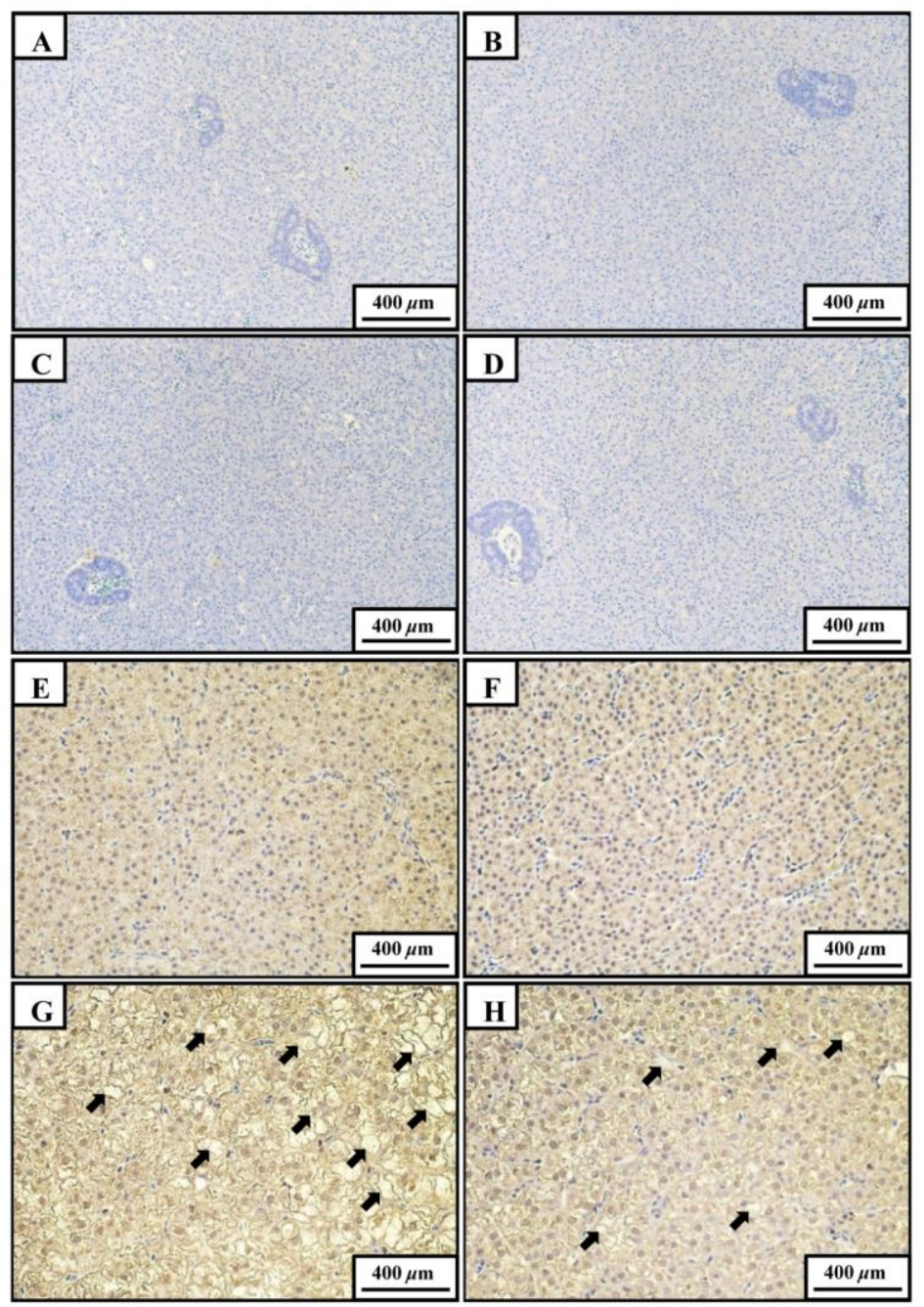

Figure 6. Localization of superoxide dismutase (SOD) in the liver of olive flounders exposed to different starvation/re-feeding protocols under different types of light. A: After 4 weeks fed under white; B: After 4 weeks fed under green LEDs (green); C: 1 week starved and 3 weeks fed under white; D: 1 week starved and 3 weeks fed under green LEDs (green); E: 2 weeks starved and 2 weeks fed under white; F: 2 weeks starved and 2 weeks fed under green LEDs (green); G: After 4 weeks starved under white; H: After 4 weeks starved under green LEDs (green). The stained cells showing brown color and arrows indicate abnormal hepatic vacuoles. Scale bars (A-H) are $400 \mu \mathrm{m}$.

between $4 \mathrm{~F}$ and $1 \mathrm{~S}-3 \mathrm{~F}$, but $2 \mathrm{~S}-2 \mathrm{~F}$ and $4 \mathrm{~S}$ showed more immunohistochemical expression of SOD in the liver. Among them, 4S showed the most immunohistochemical expression of SOD, and hepatic vacuoles were also found. The difference due to light source was not observed in $4 \mathrm{~F}$ and $1 \mathrm{~S}-3 \mathrm{~F}$, but the SOD expression in $2 \mathrm{~S}-2 \mathrm{~F}$ and $4 \mathrm{~S}$ was lower in the green LED light than in the white light.

\section{Changes in $\mathrm{H}_{2} \mathrm{O}_{2}$ and LPO Plasma Levels}

The levels of $\mathrm{H}_{2} \mathrm{O}_{2}$ and LPO did not change significantly during experimental periods in the steadily feeding group (4F), while they increased during the starvation period and then decreased during the refeeding period (Figures 7 and 8). There were significant interactive effects between factors $(P<0.05)$. However, $\mathrm{H}_{2} \mathrm{O}_{2}$ and $\mathrm{LPO}$ concentrations only returned to initial conditions in $1 \mathrm{~S}-3 \mathrm{~F}$ and tended to be lower under green LED light than under white light irradiation.

\section{Discussion}

In the present study, we investigated the effect of irradiation with white and green light on the plasma glucose and antioxidant responses during starvation and re-feeding periods in olive flounder.

During the experimental period, the weight change of $1 \mathrm{~S}-3 \mathrm{~F}$ irradiated green light was not significantly different from that of $4 \mathrm{~F}$, whereas $1 \mathrm{~S}-3 \mathrm{~F}$ irradiated with white light and $2 \mathrm{~S}-2 \mathrm{~F}$ were significantly different from $4 \mathrm{~F}$. These results suggest that the $1 \mathrm{~S}-3 \mathrm{~F}$ group has a weight change depending on the light source even if it has the same 1-week starvation period. In particular, the irradiation with green light meant that, compared with the $4 \mathrm{~F}$ group, the IS-3F group had recovered from the 1week starvation after 3-weeks' re-feeding.

Plasma glucose levels, the energy metabolism substrate in the feeding environment, were not significantly different during the experimental period in $4 \mathrm{~F}$, but significantly decreased in $4 \mathrm{~S}$. Furthermore, the 

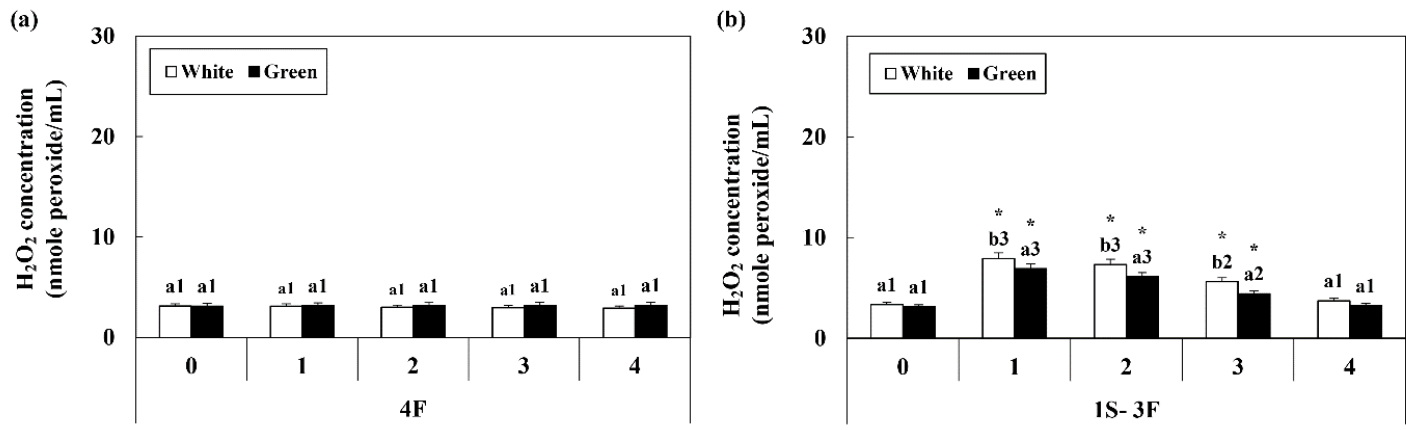

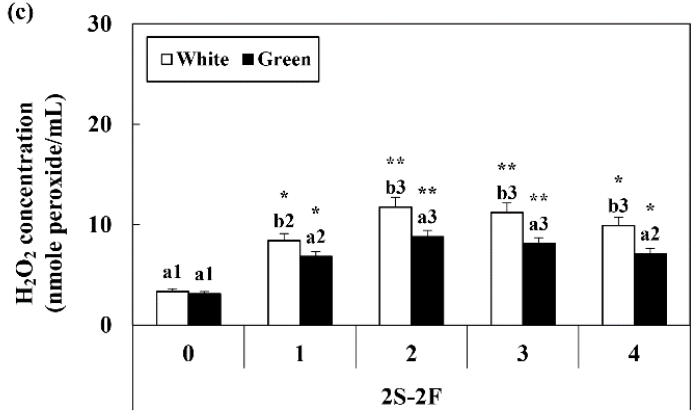

Time after experimental periods (week)

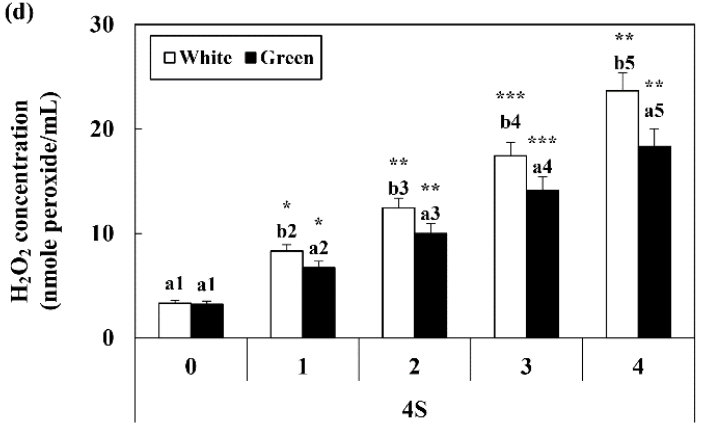

Time after experimental periods (week)

Figure 7. Concentration of plasma $\mathrm{H}_{2} \mathrm{O}_{2}$ at different starvation/re-feeding protocols under different types of light. a: 4 weeks fed (4F), b: 1 week starved and 3 weeks fed (1S-3F), c: 2 weeks starved, and 2 weeks fed (2S-2F), d: 4 weeks starved (4S), white: white fluorescent bulb, green: green wavelength LED. The different lower-case letters indicate significant differences based on exposure to the different types of light in fish within the same period $(P<0.05)$. Different numbers indicate significant differences between periods with the same light type $(P<0.05)$. Asterisk symbols $\left({ }^{*}\right)$ indicate significant differences $(\mathrm{P}<0.05)$ between different starvation / re-feeding periods within the same light type and sampling point. All values are means $\pm \operatorname{SD}(n=5)$.

(a)

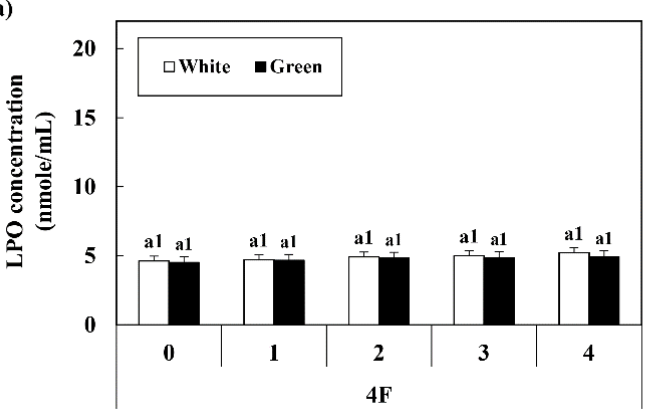

(c)

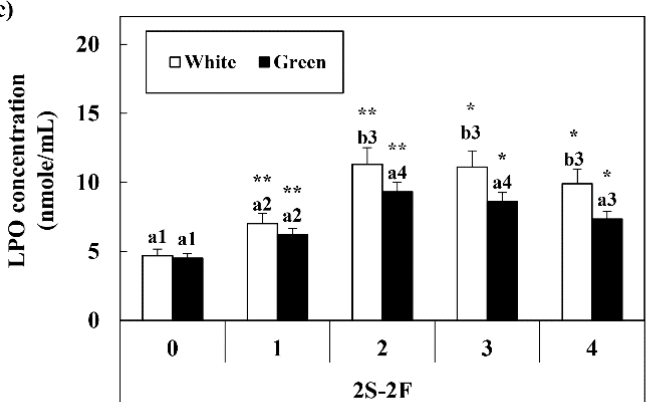

Time after experimental periods (week) (b)

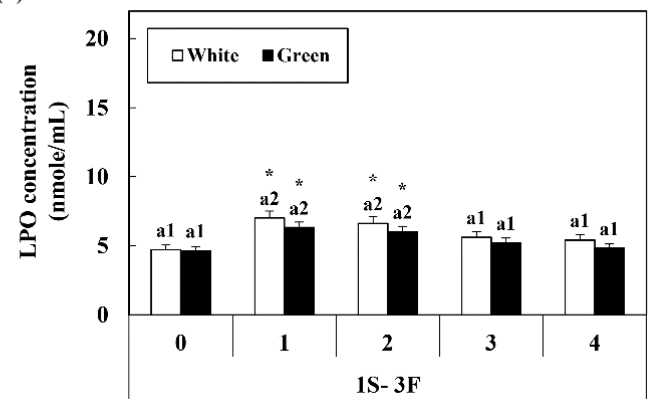

(d)

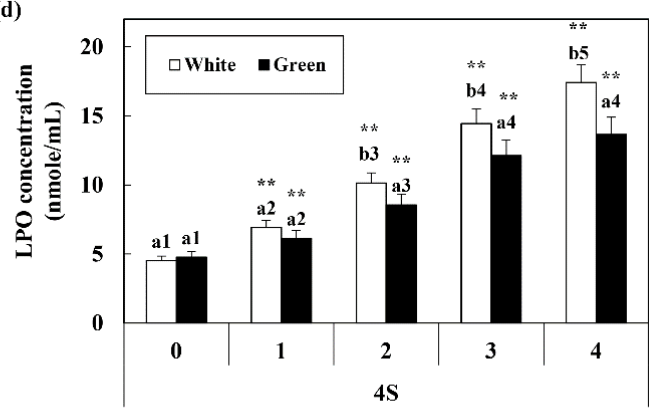

Time after experimental periods (week)

Figure 8. Concentration of plasma lipid peroxidation (LPO) at different starvation / re-feeding protocols under different types of light. a: 4 weeks fed (4F), b: 1 week starved and 3 weeks fed (1S-3F), c: 2 weeks starved, and 2 weeks fed (2S-2F), d: 4 weeks starved (4S), white: white fluorescent bulb, green: green wavelength LED. The different lower-case letters indicate significant differences based on exposure to the different types of light in fish within the same period $(P<0.05)$. Different numbers indicate significant differences between periods with the same light type $(P<0.05)$. Asterisk symbols $(*)$ indicate significant differences $(P<0.05)$ between different starvation/re-feeding periods within the same light type and sampling point. All values are means \pm SD $(n=5)$. 
glucose concentration significantly decreased in $1 \mathrm{~S}-3 \mathrm{~F}$ and $2 \mathrm{~S}-2 \mathrm{~F}$ throughout the starvation period but increased again after re-feeding. The decrease in plasma glucose levels during the starvation period is consistent with most studies in fish (Pérez-Jiménez et al., 2007; Furné et al., 2012). Furné et al. (2012) found that for sturgeon Acipenser naccarii and trout Oncorhynchus mykiss exposed to 60 days starvation and 72 days refeeding periods, plasma glucose levels dropped during the starvation period ( 1 day to 40 days) but increased during the 10-day re-feeding period.

The results of this study and previous studies suggest that fish exposed to fasting have a limited glycogenolysis process owing to insufficient glycogen in the body (Pérez-Jiménez et al., 2007) and that this also causes a decrease in glucose and an imbalance of energy homeostasis. However, during re-feeding after the starvation process, the energy source is recovered by increasing glucose levels. Choi et al. (2018) reported that, after 9-day fasting, stress increase in flounder was alleviated by green wavelength irradiation compared to blue and red wavelengths. It is established that fish generally perceive light through the eyes and pineal organ and can recognize wavelengths or light colors. Song et al. (2016) reported that the retina of fish recognizes green spectra as a stable environment that can reduce stress in the body. Therefore, green wavelength irradiation reduces the stress caused by fasting and the body glucose requirement, causing glucose concentration in the blood to be higher than under other wavelength lights.

PPARag mRNA expression was analyzed in each group. Expression levels significantly increased throughout the starvation period and decreased again after re-feeding. Furthermore, PPAR $\alpha$ mRNA expression was significantly lower under green light irradiation than under white light irradiation. Morash and McClelland (2011) analyzed PPAR $\alpha$ mRNA expression in the liver of rainbow trout after starvation for 5 weeks. They found that PPAR $\alpha$ mRNA expression was significantly higher in the starvation group than in the feeding group. The high expression of PPAR $\alpha$ in the fasting state appeared to be caused by the role of PPAR $\alpha$ in regulating gluconeogenesis to control insufficient energy homeostasis in the body (Morash \& McClelland, 2011). Therefore, considering that PPAR $\alpha$ is increased in order to increase the insufficient glucose concentration caused by the starvation environment, PPAR $\alpha$ is a key sensor for metabolic adaptation and maintenance of energy homeostasis. However, PPAR $\alpha$ expression was significantly lower under green wavelength irradiation, which is considered to be caused by a stress reduction.

Antioxidant enzymes, SOD and CAT MRNA, were analyzed to assess their activity in response to starvation stress. It was found that the expression levels of these antioxidant enzymes significantly increased throughout the starvation period and decreased again after refeeding. Moreover, antioxidant enzyme expression was significantly lower under the green wavelength than under the other light source.

Babaei et al. (2016) showed significantly higher SOD and CAT activities in the fasting experimental group than in the feeding experimental group of Siberian sturgeon Acipenser baerii after a 2-week fasting period, but SOD and CAT expression levels significantly decreased on re-feeding. Choi et al. (2018) reported that the expression level of antioxidant enzymes in flounder decreased only under green wavelength irradiation after fasting for 9 days.

In this study, IHC staining was performed to determine differences in the expression of SOD in the liver. During the starvation period, a large amount of SOD stained with brown colors was observed. However, brown stained expressions of SOD were remarkably lower in the experimental group irradiated with green wavelength than in the group under fluorescent lamps. In particular, in the liver cells of 45 , the formation of abnormal hepatic vacuoles was observed when the nutrients and growth factors were insufficient. However, the size and number of vacuoles and the expression of SOD decreased significantly in the liver of the $4 S$ experimental group under green wavelength irradiation.

Mohapatra et al. (2015) observed through IHC staining that red sea bream Pagrus major starved for 10 days presented a larger amount of SOD than the control. These results suggest that starvation not only induced abnormal vacuoles in liver cells but also induces apoptosis. Subsequently, the SOD mRNA expression and plasma level increased are consistent with the increase of immunoreactive cells, suggesting that SOD increases in the liver are part of the antioxidant coping mechanism. In this study, the expression level of antioxidant enzymes in the liver changed depending on the feeding environment. Additionally, green wavelengths seemed to reduce the expression of SOD, the antioxidant enzyme in the liver, by alleviating the stress of fish exposed to the starvation environment. Therefore, if green wavelength irradiation is administered to fish exposed to the starvation environment, it will be possible to reduce levels of antioxidant enzymes and stress caused by the starvation environment.

Like the antioxidant enzymes, the concentration of $\mathrm{H}_{2} \mathrm{O}_{2}$, which is one type of ROS, and LPO, a type of oxidative stress, increased during the starvation period. However, $\mathrm{H}_{2} \mathrm{O}_{2}$ and LPO concentrations decreased under green wavelength irradiation. Robinson et al. (1997) reported that the starvation environment induced reactive oxygen in the body, which not only damaged the nucleic acid but also caused many physiological disorders. Choi et al. (2012) confirmed the effect of various light sources on ROS and LPO produced by starvation. In their study, cinnamon clownfish increased the LPO concentration by increased $\mathrm{H}_{2} \mathrm{O}_{2}$ production during a 12-day starvation period, however, green wavelength irradiation caused a decrease in $\mathrm{H}_{2} \mathrm{O}_{2}$ 
and LPO concentration compared to other wavelengths. Therefore, starvation seems to act as a pro-oxidative effect by increasing $\mathrm{H}_{2} \mathrm{O}_{2}$ and $\mathrm{LPO}$ concentration in the body and increases reactive oxygen species and oxidative stress, which can then be reduced by refeeding. Green wavelengths can positively control starvation-induced antioxidant responses, and this suggests that starvation-induced oxidative stress can be suppressed, and ROS production can be reduced.

The results of this study suggest that starvation caused oxidative stress in the juvenile flounder, but this oxidative stress was reduced by re-feeding. Additionally, green wavelength irradiation inhibited starvationinduced oxidative stress. Moreover, it promoted fish recovery from lowered antioxidant ability by inducing a faster reduction of oxidative stress after re-feeding than occurred in fish under a white light source. In conclusion, the fish experience extreme stress as the starvation period increases. Although the stress increased during long-term starvation, it was confirmed that the oxidative stress and ROS were reduced by the green wavelength and that this effect was enhanced as the exposure period for the green wavelength increased. Further studies are needed to assess the effects of longer starvation and re-feeding periods in various developmental stages, so the changes in the physiological responses of this species can be assessed in more detail.

\section{Conclusion}

In this study, when starvation and re-feeding in four different feeding regimes were performed with irradiation by white or green light, it was confirmed that oxidative stress was induced due to fasting in all experimental groups. However, the experimental group irradiated with a green wavelength expressed less oxidative stress than the group irradiated with white light. In addition, it suggests the possibility of being able to use green light irradiation to reduce stress generated through an unintended fasting period due to external changes in the aquaculture environment. This result suggests that green light it will help to produce healthier fish.

\section{Acknowledgements}

This research was supported by the project titled 'Development and commercialization of high density low-temperature plasma-based seawater sterilization purification system' funded by the Ministry of Oceans and Fisheries, Korea.

\section{References}

Ali, T.E.S., Martínez-Llorens, S., Moñino, A.V., Cerdá, M.J., \& Tomás-Vidal, A. (2016). Effects of weekly feeding frequency and previous ration restriction on the compensatory growth and body composition of Nile tilapia fingerlings. Egyptian Journal of Aquatic Research, 42(3), 357-363. http://doi.org/10.1016/j.ejar.2016.06.004

Antonopoulou, E., Kentepozidou, E., Feidantsis, K., Roufidou, C., Despoti, S., \& Chatzifotis, S. (2013). Starvation and refeeding affect Hsp expression, MAPK activation and antioxidant enzymes activity of European Sea Bass Dicentrarchus labrax. Comparative Biochemistry Physiology Part C, 165(1), 79-88. http://doi.org/10.1016/j.cbpa.2013.02.019

Babaei, S., Kenari, A.A., Hedayati, M., Sadati, M.A.Y., \& Meton, I. (2016). Effect of diet composition on growth performance, hepatic metabolism and antioxidant activities in Siberian sturgeon (Acipenser baerii, Brandt, 1869) submitted to starvation and refeeding. Fish Physiology Biochemistry, 42(6), 1509-1520. http://doi.org/10.1007/s10695-016-0236-0

Bar, N. (2014). Physiological and hormonal changes during prolonged starvation in fish. Canadian Journal of Fisheries Aquatic Sciences, 71(10), 1447-1458. http://doi.org/10.1139/cjfas-2013-0175

Choi, C.Y., Choi, J.Y., Choi, Y.J., \& Yoo, J.H. (2018). Physiological effects of various light spectra on oxidative stress by starvation in olive flounder Paralichthys olivaceus. Molecular Cellular Toxicology, 14(4), 399-408. http://doi.org/10.1007/s13273-018-0044-y

Choi, C.Y., Shin, H.S., Choi, Y.J., \& Kim, N.N. (2012). Effect of LED light spectra on starvation-induced oxidative stress in the cinnamon clownfish Amphiprion melanopus. Comparative Biochemistry Physiology Part A, 163(3-4), 357-363. http://doi.org/10.1016/j.cbpa.2012.07.005

Furné, M., Morales, A.E., Trenzado, C.E., Garcia-Gallego, M., Hidalgo, M.C., Domezain, A., \& Rus, A.S. (2012). The metabolic effects of prolonged starvation and refeeding in sturgeon and rainbow trout. Journal of Comparative Physiology B, 182(1), 63-76. http://doi.org/10.1007/s00360-011-0596-9

Griffin, I.J. (2015). Catch-Up Growth: Basic Mechanisms. Nestle Nutrition Institute Workshop Series, 81, 87-97. https://doi.org/10.1159/000365806

Kim, T., \& Yang, Q. (2013). Peroxisome-proliferator-activated receptors regulate redox signaling in the cardiovascular system. World Journal of Cardiology, 5(6), 164-174. http://doi.org/10.4330/wjc.v5.i6.164

Li, G., Brocker, C. N., Yan, T., Xie, C., Krausz, K. W., Xiang, R., \& Gonzalez, F. J. (2017). Metabolic adaptation to intermittent fasting is independent of peroxisome proliferator activated receptor alpha. Molecular Metabolism, 7, 80-89. http://doi.org/10.1016/j.molmet.2017.10.011

Mohapatra, S., Chakraborty, T., Shimizu, S., Urasaki, S., Matsubara, T., Nagahama, Y., \& Ohta, K. (2015). Starvation beneficially influences the liver physiology and nutrient metabolism in Edwardsiella tarda infected red sea bream Pagrus major. Comparative Biochemistry Physiology Part A, 189, 110. http://doi.org/10.1016/j.cbpa.2015.07.003

Morash, A. J., \& McClelland, G. B. (2011). Regulation of carnitine palmitoyltransferase (CPT) I during fasting in rainbow trout Oncorhynchus mykiss promotes increased mitochondrial fatty acid oxidation. Physiological and Biochemical Zoology, 84(6), 625-633. http://doi.org/10.1086/662552 
Najafi, A., Salati, A.P., Yavari, V., \& Asadi, F. (2014). Effects of short-term starvation and re-feeding on antioxidant defense status in Mesopotamichthys sharpeyi (Günther, 1874) fingerlings. International Journal of Aquatic Biology, 2(5), 246-252. http://doi.org/10.22034/ijab.v2i5.136

Pandey, S., Parvez, S., Sayeed, I., Haques, R., Bin-Hafeez, B., \& Raisuddin, S. (2003). Biomarkers of oxidative stress: a comparative study of river Yamuna fish Wallago attu (BI. \& Schn.). Science of the Total Environment, 309(1-3), 105-115. http://doi.org/10.1016/S0048-9697(03)000068

Pérez-Jiménez, A., Guedes, M.J., Morales, A.E., \& Oliva-Teles, A. (2007). Metabolic responses to short starvation and refeeding in Dicentrarchus labrax. Effect of dietary composition. Aquaculture, 265(1-4), 325-335. http://doi.org/10.1016/j.aquaculture.2007.01.021

Picard, F., \& Auwerx, J. (2002). PPARy and glucose homeostasis. Annual Review of Nutrition 22, 167-97. http://doi.org/10.1146/annurev.nutr.22.010402.10280 8

Rakhshandehroo, M., Knoch, B., Muller, M., \& Kersten, S. (2010). Peroxisome Proliferator-Activated receptor alpha target genes. PPAR Research, 2010, 20. https://doi.org/10.1155/2010/612089

Regoli, F., \& Giuliani, M. E. (2014). Oxidative pathways of chemical toxicity and oxidative stress biomarkers in marine organisms. Marine Environmental Research, 93, 106-117.

http://doi.org/10.1016/j.marenvres.2013.07.006

Robinson, M.K., Rustum, R.R., Chambers, E.A., Rounds, J.D., Wilmore, D.W., \& Jacobs, D.O. (1997). Starvation enhances hepatic free radical release following endotoxemia. Journal of Surgical Research, 69(2), 325330. http://doi.org/10.1006/jsre.1997.5062

Shin, H.S., Lee, J.H., \& Choi, C.Y. (2012). Effects of LED light spectra on the growth of the yellowtail clownfish Amphiprion clarkii. Fisheries Sciences, 78(3), 549-556. http://doi.org/10.1007/s12562-012-0482-8

Song, J.A., Kim, N.N., Choi, Y.J., \& Choi, C.Y. (2016). Effect of green light spectra on the reduction of retinal damage and stress in goldfish, Carassius auratus. Biochemical and biophysical research communications, 476(2), 96101. https://doi.org/10.1016/j.bbrc.2016.05.049

Won, E.T., \& Borski, R.J. (2013). Endocrine regulation of compensatory growth in fish. Frontiers in Endocrinology, 4, 1-13. http://doi.org/10.3389/fendo.2013.00074

Yang, S., He, K., Yan, T., Wu, H., Zhou, J., Zhao, L., Wang, Y., \& Gong, Q. (2019). Effect of starvation and refeeding on oxidative stress and antioxidant defenses in Yangtze sturgeon Acipenser dabryanus. Fish Physiology and Biochemistry, 45(3), 987-995. http://doi.org/10.1007/s10695-019-0609-2 